\title{
Evaporation of Phosphorus in Molten Silicon by an Electron Beam Irradiation Method*1
}

\author{
Kazuhiro Hanazawa, Noriyoshi Yuge*2 and Yoshiei Kato*3 \\ Steel Research Laboratory, JFE Steel Corporation, Chiba 260-0835, Japan
}

The evaporation behavior of phosphorus in molten silicon during electron beam irradiation was investigated with the aim of producing solar grade silicon (SOG-Si) from metallurgical grade silicon (MG-Si) by a sequential metallurgical process. Batch experiments showed that the evaporation rate of phosphorus increased in proportion to the power of the electron beam and phosphorus content. The phosphorus removal rate was controlled by free evaporation from the molten silicon surface. Electron beam irradiation makes it possible to secure a higher temperature at the free liquid surface, which results in more efficient dephosphorization. A continuous flow experiment indicated that the phosphorus concentration at the outlet increased when the silicon feed rate was raised, which was attributed to the fact that the hearth residence time of the molten silicon was proportionally shorter. Thus, the flow of molten silicon in the hearth did not behave as a complete mixed reactor flow type reaction, but was close to a plug flow type reaction. With a $150 \mathrm{~kg}$ scale pilot manufacturing plant, MG-Si containing about 25 mass ppm of phosphorus was successfully purified to $\mathrm{P}<0.1$ mass ppm.

(Received November 11, 2003; Accepted December 26, 2003)

Keywords: phosphorus, silicon, electron beam, vapor pressure, vacuum, solar grade silicon, metallurgical grade silicon

\section{Introduction}

Photovoltaic power generation has been an object of intense interest in recent years as one approach to solving environmental and energy problems, and is rapidly gaining popularity as a residential power source. At present, off-spec silicon scrap from the semiconductor industry is the main material for solar grade silicon (SOG-Si) in multi-crystalline wafers, which are applied most universally in solar cells. However, sharply rising demand in recent years, it has become increasingly difficult to secure an adequate supply of off-spec silicon. Thus, an economical mass production process for SOG-Si has been desired.

The authors developed a metallurgical process for producing high-purity SOG-Si from commercially available metallurgical grade silicon (MG-Si). ${ }^{1,2)}$ When using MG-Si, it is necessary to remove a variety of impurities from the feedstock to levels which satisfy the purity requirements of SOG-Si. For example, when using MG-Si with a phosphorus content of 30 mass ppm, the targeted P content of SOG-Si material is below 0.1 mass ppm, ${ }^{3)}$ and the allowable P content of the SOG-Si wafer for obtaining $95 \%$ of the maximum conversion efficiency (conversion ratio of solar to electric energy) with $0 \% \mathrm{P}$ is below 0.012 mass ppm. ${ }^{4)}$

Directional solidification is used to remove certain impurities, but is not effective for dephosphorization of molten silicon because the equilibrium partition coefficient of $\mathrm{P}$ is $0.35 .^{5)}$ High frequency vacuum melting and resistor heating ${ }^{6,7)}$ and electron beam (EB) melting ${ }^{8)}$ were investigated as possible phosphorous removal techniques. However, with vacuum melting, the phosphorous removal rate was slow, and with the EB technique, the final P content was

\footnotetext{
*1 This Paper was Originally Published in Japanese in J. Japan Inst. Metals 67 (2003) 569-574

${ }^{*}$ Present address: Planning and Administration Division, JFE R\&D Corporation. Kawasaki 210-0855, Japan

${ }^{*}$ Present address: Patent \& Technical Information Business Division, Kawasaki Steel Techno-Research Corporation, Tokyo 100-0005, Japan
}

3-6 mass ppm, which does not achieve the targeted $\mathrm{P}$ content for SOG-Si.

We therefore studied EB melting dephosphorization in batch and continuous flow experiments at the laboratory scale in order to clarify the de-P mechanism and verify the feasibility of this technique as a mass production technology.

\section{Experimental Procedure}

\subsection{Experimental apparatus}

Schematic views of the apparatus for the batch and continuous flow experiments are shown in Figs. 1 and 2, respectively. The basic equipment consisted of an EB gun, vacuum chamber, vacuum pumps (rotary, oil diffusion, and turbo molecular pumps), and a hearth (water-cooled copper or graphite hearth). A sampling and temperature measuring device was also used in the batch experiments, and a continuous feeder, hearth for silicon melting, and water-

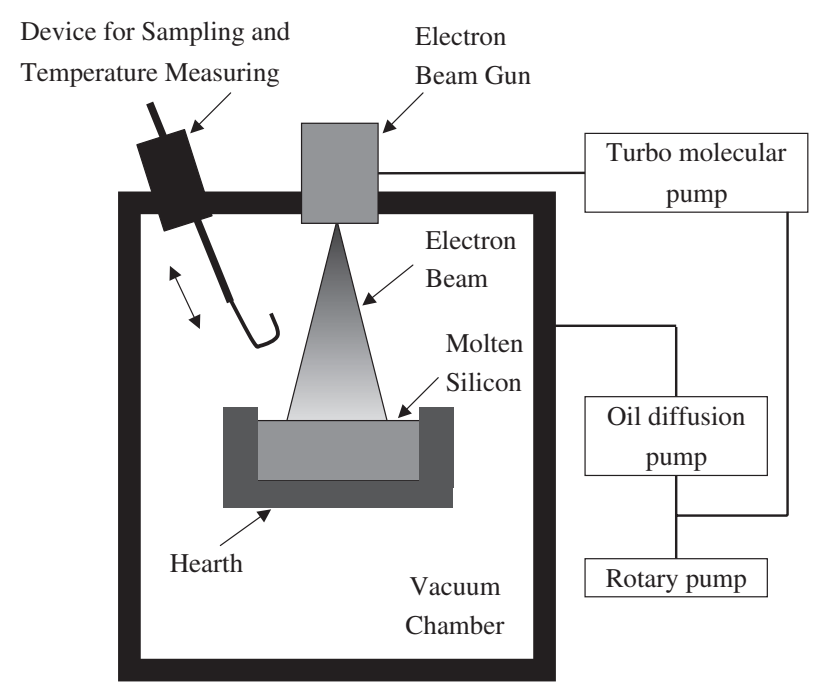

Fig. 1 Experimental procedure for batch melting by electron beam. 


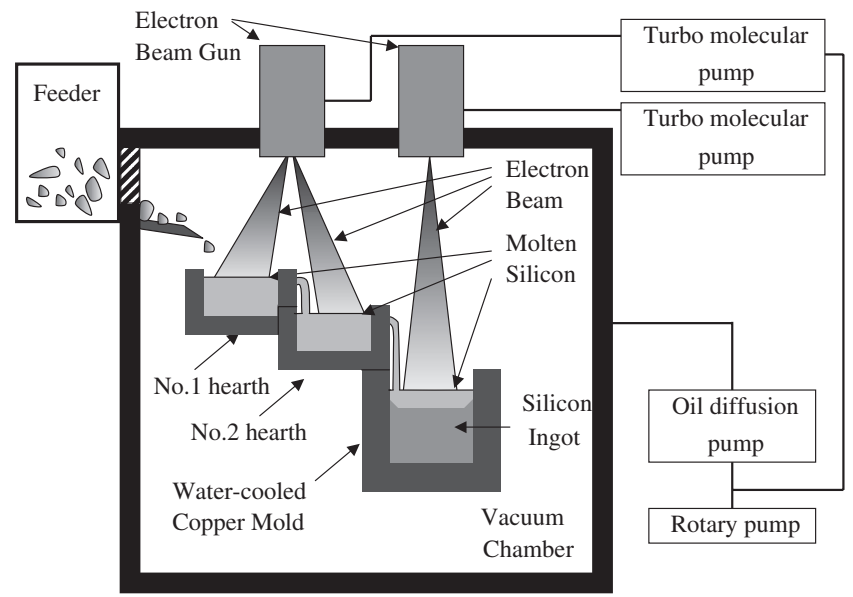

Fig. 2 Experimental procedure for continuous melting by electron beam.

cooled copper mold for continuous silicon tapping were provided for the continuous flow experiments. The molten silicon moves between the hearths for silicon melting and dephosphorization and the water-cooled copper mold for tapping by overflow. At the water-cooled copper mold for directional solidification, the silicon melt is irradiated with another EB. ${ }^{9)}$

MG-Si of $99 \%$ purity was used in these experiments. The impurity contents of the MG-Si usually used in experiments are $\mathrm{P} / 25-30, \mathrm{~B} / 5-10, \mathrm{Fe} / 1000-1500, \mathrm{Al} / 600-800$, Ti/150 200 , and $\mathrm{C} / 150-250$ mass ppm, but those for the batch experiment with the water-cooled hearth were $\mathrm{P} / 20-27, \mathrm{~B} /$ 22-30, Fe/440-600, Al/570-900, Ti/30-60, and C/500830 mass ppm. Phosphorous contents above 1 mass ppm were analyzed by the ICP (Induced Coupled Plasma) atomic emission spectrometry method, and those below 1 mass ppm were analyzed by ICP mass spectrometry.

\subsection{Batch experiments}

The conditions used in the batch experiments are shown in Table 1. The mass of silicon, EB power, and surface area of the silicon in the hearth were varied in the range of 1.2$6.6 \mathrm{~kg}, 20-100 \mathrm{~kW}$, and $0.022-0.075 \mathrm{~m}^{2}$, respectively, in the laboratory scale experiments, whereas values of $45 \mathrm{~kg}$, 190$210 \mathrm{~kW}$, and $0.40 \mathrm{~m}^{2}$ were used in the industrial scale experiments. After charging the given amount of MG-Si into the water-cooled or graphite hearth, the chamber was evacuated by the vacuum pumps to a pressure of $10^{-3}$ to $10^{-2} \mathrm{~Pa}$. The EB was then irradiated on the MG-Si, and sampling and temperature measurements were performed intermittently to examine dephosphorization behavior. Evaporation of silicon due to EB irradiation was calculated from the difference in mass before and after the experiment. The EB irradiation pattern was a sine curve in the laboratory scale experiments and spiral curve toward the center in the industrial scale experiments.

\subsection{Continuous flow experiment}

The experimental conditions used with the continuous feed process are shown in Table 2. Two hearths were used, No. 1 hearth for silicon melting and No. 2 hearth for phosphorous removal. The silicon feed rate, EB power for phosphorous removal, and surface area of the silicon in No. 2 hearth were varied in the range of $2-12 \mathrm{~kg} / \mathrm{hr}, 80 \mathrm{~kW}$, and $0.04 \mathrm{~m}^{2}$ in the laboratory scale experiments and $16-70 \mathrm{~kg} / \mathrm{hr}, 220-250 \mathrm{~kW}$, and $0.4 \mathrm{~m}^{2}$ in the industrial scale experiments. After initially melting silicon in the hearth to begin the process, MG-Si was continuously charged to No. 1 hearth. Experiments were

Table 1 Experimental condition of batch process.

\begin{tabular}{cccc}
\hline & \multicolumn{2}{c}{ Laboratory scale } & Industrial scale \\
\hline Mass of $\mathrm{Si}, W_{\mathrm{si}} / \mathrm{kg}$ & $1.2,2.4$ & $2.2,4.4,6.6$ & 45 \\
\hline EB power, $P_{\mathrm{EB}} / \mathrm{kW}$ & $30,60,80,100$ & $20-90$ & 190,210 \\
\hline EB irradiation pattern & \multicolumn{2}{c}{ Sine curve } & Spiral \\
\hline Chamber pressure $/ \mathrm{Pa}$ & \multicolumn{2}{c}{$1.3 \times 10^{-2}-6.7 \times 10^{-2}$} & $2.7 \times 10^{-2}-8.0 \times 10^{-2}$ \\
\hline Surface area of $\mathrm{Si}, A / \mathrm{m}^{2}$ & \multicolumn{2}{c}{0.040} & $0.022,0.050,0.075$ \\
\hline Material of hearth & Water-cooled copper & Graphite & Graphite \\
\hline
\end{tabular}

Table 2 Experimental condition of continuos feed process.

\begin{tabular}{|c|c|c|c|}
\hline & & Laboratory scale & Industrial scale \\
\hline \multicolumn{2}{|c|}{ Supplied rate of $\mathrm{Si}, F_{\mathrm{si}} / \mathrm{kgh}^{-1}$} & $2-12$ & $16-70$ \\
\hline \multicolumn{2}{|c|}{ Chamber pressure/Pa } & $1.3 \times 10^{-2}-6.7 \times 10^{-2}$ & $1.3 \times 10^{-2}-8.0 \times 10^{-2}$ \\
\hline \multirow{3}{*}{$\begin{array}{c}\text { No. } 1 \text { hearth } \\
\text { (melting) }\end{array}$} & EB power, $P_{\mathrm{EB}} / \mathrm{kW}$ & 20 & 80 \\
\hline & EB irradiation pattern & Sine curve & Spiral \\
\hline & Surface area of $\mathrm{Si} / \mathrm{m}^{2}$ & 0.010 & 0.10 \\
\hline \multirow{4}{*}{$\begin{array}{l}\text { No. } 2 \text { hearth } \\
\text { (Phosphorus } \\
\text { removal) }\end{array}$} & EB power, $P_{\mathrm{EB}} / \mathrm{kW}$ & 80 & 220,250 \\
\hline & EB irradiation pattern & Sine curve & Spiral \\
\hline & Surface area of $\mathrm{Si} / \mathrm{m}^{2}$ & 0.040 & 0.40 \\
\hline & Material of hearth & Copper & Graphite \\
\hline
\end{tabular}


terminated when the mass of silicon in the water-cooled mold reached approximately $20 \mathrm{~kg}$ in the laboratory scale experiments and $150 \mathrm{~kg}$ in the industrial scale experiments. De-P behavior was also examined in the case of EB irradiation of the silicon in the water-cooled mold. The $\mathrm{P}$ content of the silicon was analyzed in the MG-Si, silicon added at the overflow mouth of No. 1 and No. 2 hearths, and silicon ingot in the water-cooled mold.

\section{Results and Discussions}

\subsection{Batch experiments}

\subsubsection{Chemical composition of evaporated silicon and dephosphorization rate}

Evaporated silicon adhering to the inner wall of the chamber was collected and analyzed after the laboratory scale experiment with the water-cooled copper hearth. Table 3 shows the contents of impurities in the raw and evaporated silicon. The contents of phosphorous, aluminum, and calcium, which have high vapor pressures, ${ }^{10)}$ increase remarkably in the evaporated silicon, which means that evaporation is effective for eliminating these impurities from silicon.

Figure 3 shows the relationship between the $P$ content normalized for the initial content, $[P]_{0}$, and EB irradiation time in the laboratory scale experiment on semilogarithmic scales. The $P$ content decreased linearly with time. Thus, the dephosphorization rate is proportional to the phosphorous content, as is also the case in the high frequency vacuum induction melting method, ${ }^{6,7)}$ and is given by the following equation:

Table 3 Impurities contents of raw and evaporated silicon.

\begin{tabular}{ccccccccc} 
& \multicolumn{1}{c}{} & & \multicolumn{3}{c}{ (mass ppm) } \\
\hline & $\mathrm{P}$ & $\mathrm{Al}$ & $\mathrm{Ca}$ & $\mathrm{Cu}$ & $\mathrm{C}$ & $\mathrm{Fe}$ & $\mathrm{Ti}$ & $\mathrm{B}$ \\
\hline $\begin{array}{c}\text { Metallurgical } \\
\text { grade silicon }\end{array}$ & 27 & 860 & 100 & $<1$ & 800 & 470 & 23 & 23 \\
\hline $\begin{array}{c}\text { Evaporated } \\
\text { silicon }\end{array}$ & 118 & 2799 & 1247 & 72 & 3193 & 587 & 24 & $<1$ \\
\hline
\end{tabular}

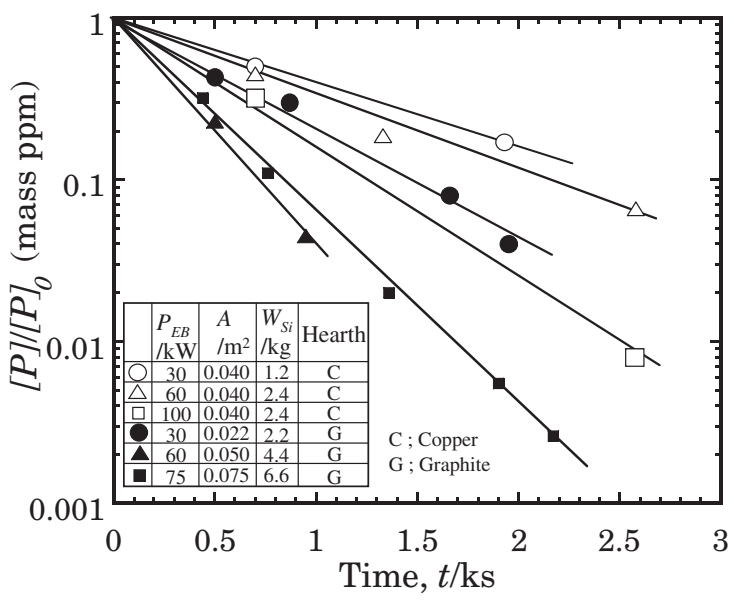

Fig. 3 Relation between phosphorus content and treatment time.

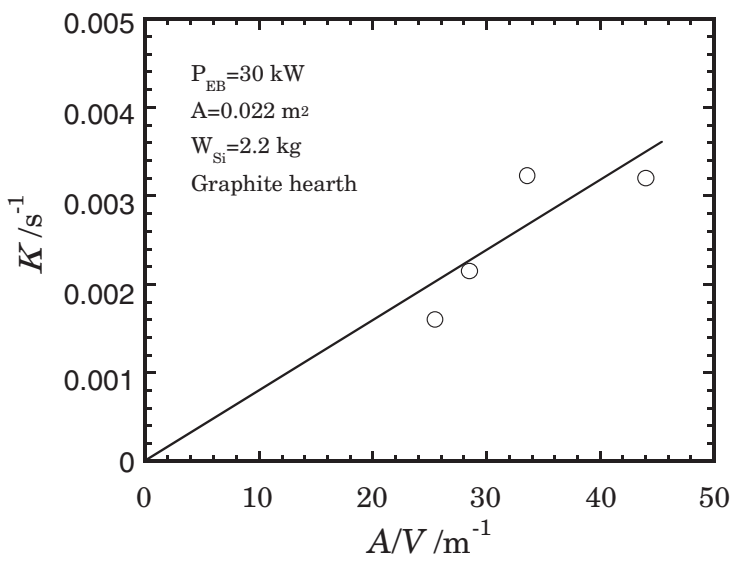

Fig. 4 Relation between $K$ and $A / V$.

$$
\begin{aligned}
& -\mathrm{d}[P] / \mathrm{d} t=K[P] \\
& K=k_{\mathrm{P}}(A / V)
\end{aligned}
$$

where $[P]$ is the phosphorous content (mass ppm), $K$ is the rate constant $\left(\mathrm{s}^{-1}\right)$ for dephosphorization, $k_{\mathrm{P}}$ is a rate constant $(\mathrm{m} / \mathrm{s})$ of the first order reaction, $A$ is the interface area $\left(\mathrm{m}^{2}\right)$ of the dephosphorization reaction, and $V$ is the volume $\left(\mathrm{m}^{3}\right)$ of molten silicon in the hearth.

Figure 4 shows the dependence of $A / V$ on $K$ for a surface area of $0.022 \mathrm{~m}^{2}$ of molten silicon in the graphite hearth and $30 \mathrm{~kW}$ of EB power. As predicted from eq. (2), $K$ is proportional to $1 / \mathrm{V}$.

\subsubsection{Effects of EB irradiation power density and hearth material on dephosphorization rate and evapora- tion rate of silicon}

The de-P rate can be increased by raising the temperature at the reaction interface, as estimated from the high vapor pressure of phosphorous. Figure 5 shows the relationship between $k_{\mathrm{P}}$ and EB power density, defined as EB power divided by the interface area of the de- $P$ reaction in the hearth. The de- $P$ rate for each experimental condition varies proportionately with $\left(P_{\mathrm{EB}} / A\right)^{1.75}$, where $P_{\mathrm{EB}}$ is $\mathrm{EB}$ power $(\mathrm{kW})$. The locally higher temperature at the free silicon

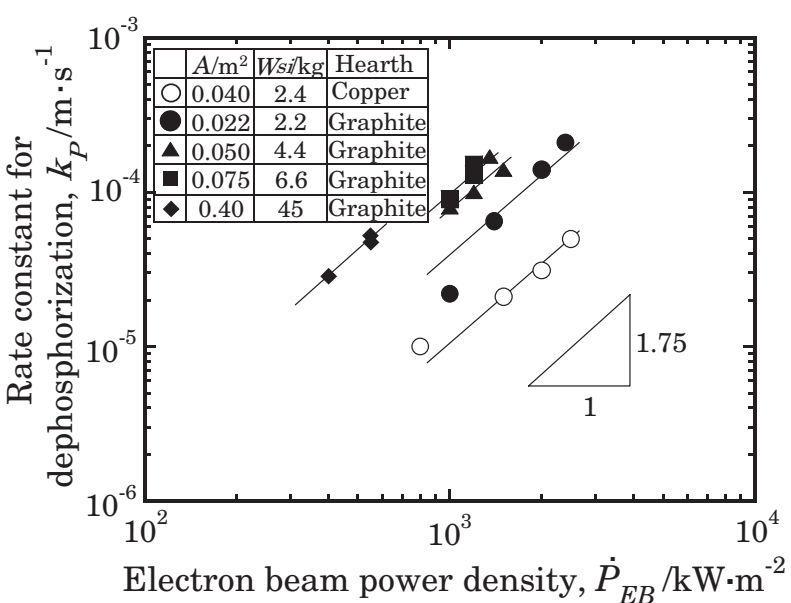

Fig. 5 Relation between rate constant for dephosphorization and electron beam power density. 


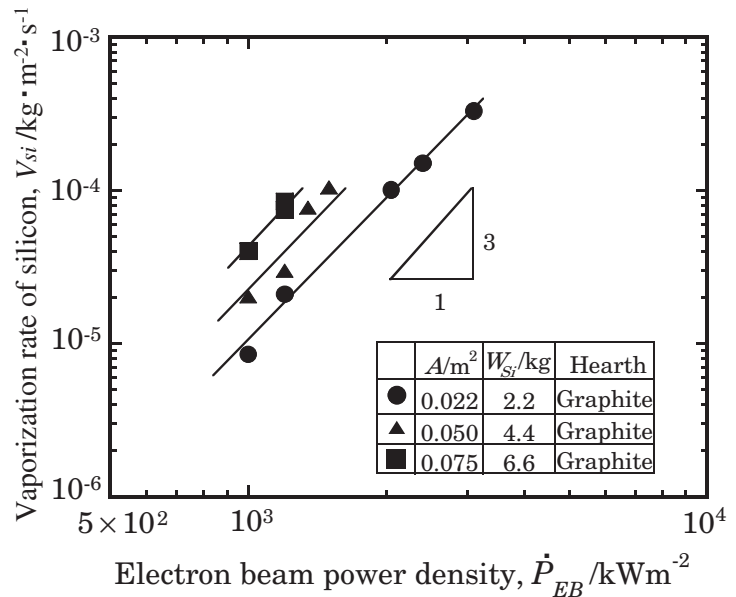

Fig. 6 Relation between vaporization rate of silicon and electron beam power density.

surface irradiated by the EB increases the dephosphorization rate. As seen in the plots of $\bigcirc$ and $\bullet$, which have almost the same interfacial area, $A\left(\mathrm{~m}^{2}\right)$, and mass of silicon, $W_{\mathrm{Si}}(\mathrm{kg})$, the de- $P$ rate is higher with the graphite hearth than with the water-cooled copper hearth.

The relationship between the vaporization rate, $V_{\mathrm{Si}}(\mathrm{kg} /$ $\mathrm{m}^{2} \mathrm{~s}$ ), of silicon and EB power density in the graphite hearth is shown in Fig. 6. Like the de- $P$ rate, $V_{\mathrm{Si}}$ also increases as the EB power density, free surface area, and mass of silicon increase. From Fig. $6, V_{\mathrm{Si}}$ is proportional to the cube of the EB power density.

\subsubsection{Rate-determining step of dephosphorization and bath temperature}

Free evaporation through the free surface of the molten silicon can be assumed to be the rate-controlling step in silicon vaporization because $V_{\mathrm{Si}}$ appears not to be affected by diffusion of silicon in the gas and liquid phases. Thus, $V_{\mathrm{Si}}$ can be expressed by the Hertz-Knudsen-Langumuir equation as follows.

$$
\begin{aligned}
& V_{\mathrm{Si}}=4.37 \times 10^{4} \cdot P_{\mathrm{Si}} \cdot\left(M_{\mathrm{Si}} / T\right)^{1 / 2} \\
& \log P_{\mathrm{Si}}=-20900 / T-0.565 \times \log T+12.9
\end{aligned}
$$

where $P_{\mathrm{Si}}$ is the vapor pressure (Pa) of phosphorous, $M_{\mathrm{Si}}$ is the atomic weight of silicon, and $T$ is the free surface temperature $(\mathrm{K})$ of the molten silicon. Equation (4) is supported by a database collected by Kubachewski et al. ${ }^{10)}$

Figure 7 shows the surface temperature calculated from eqs. (3) and (4) using the measured silicon vaporization and the bulk temperatures estimated from the measured carbon content and measured by thermocouple. The bulk temperature estimated from the carbon content is obtained from the following equation for saturated carbon solubility. ${ }^{11)}$

$$
\log [C] / 1000=3.63-9660 / T
$$

As seen in Fig. 7, the estimated surface temperature is 250-400 K higher than the bulk temperature, although there is a temperature difference of $90-130 \mathrm{~K}$ between the temperature measured by thermocouple and that estimated from the carbon content. Increasing the EB power density contributes to higher temperatures both at the surface and in the bulk.

In the EB melting process, the evaporation rate of

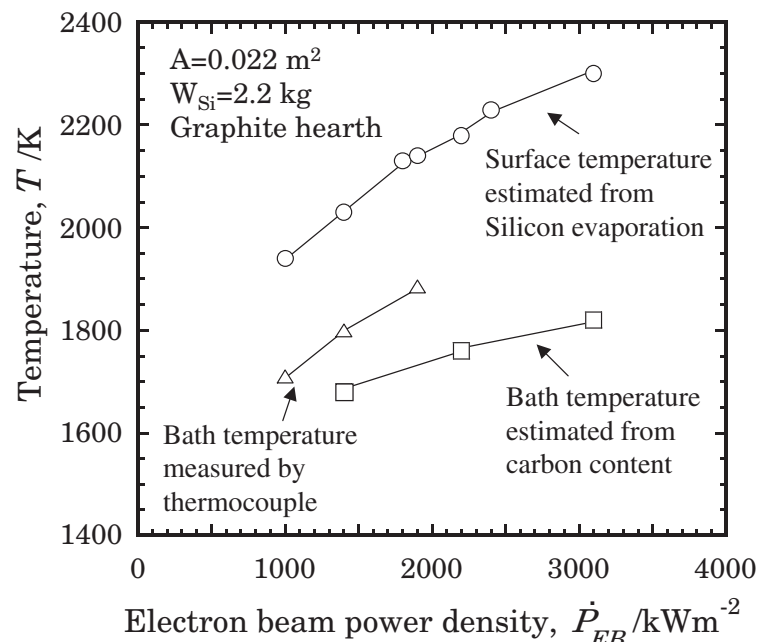

Fig. 7 Relation between temperature of molten silicon and electron beam power density.

vaporized components is controlled by free evaporation, ${ }^{12)}$ diffusion in the liquid phase, ${ }^{13)}$ or both. ${ }^{14)}$ Equations (6) and (7) are obtained ${ }^{15)}$ on the assumption that free evaporation of phosphorous is the rate-determining step in dephosphorization.

$$
\begin{aligned}
& k_{\mathrm{P}}=4.44 \times 10^{4} \exp \left(\Delta G^{0} / R T\right) \cdot\left(1 / \rho_{\mathrm{Si}}\right)\left(M_{\mathrm{P}} / T\right)^{1 / 2} \\
& \Delta G^{0}=-387000+103 T
\end{aligned}
$$

where $\Delta G^{0}$ is the change of free energy for the $P(g)=P$ reaction $(\mathrm{J} / \mathrm{mol}), \rho_{\mathrm{Si}}$ is the density of molten silicon $\left(\mathrm{kg} / \mathrm{m}^{3}\right)$, and $M_{\mathrm{P}}$ is the atomic weight of phosphorous (-). Figure 8 shows the relationship between $k_{\mathrm{P} \text {,calc. }}$ and $k_{\mathrm{P} \text {,meas. }}$. The value of $k_{\mathrm{P}, \text { calc. }}$ is obtained by substituting $T$ calculated from eqs. (3)-(4) and the measured value of $V_{\mathrm{Si}}$, into eqs. (6)-(7), and the value of $k_{\mathrm{P} \text {,meas. }}$ is obtained from eqs. (1)-(2). As seen in Fig. $8, k_{\mathrm{P} \text {,calc. }}$ and $k_{\mathrm{P} \text {,meas. }}$ show good agreement over a wide range, which means the de- $P$ rate is controlled by free evaporation.

\subsubsection{Comparison of EB melting process and vacuum induction process in de- $P$ process}

The relationship between the dephosphorization rate and molten silicon bath temperature is shown in Fig. 9, which

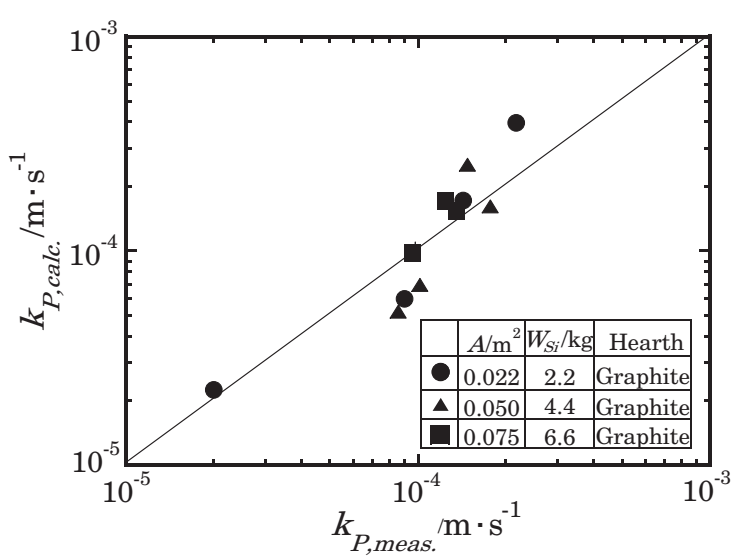

Fig. 8 Relation between calculated and measured rate constant for dephosphorization. 


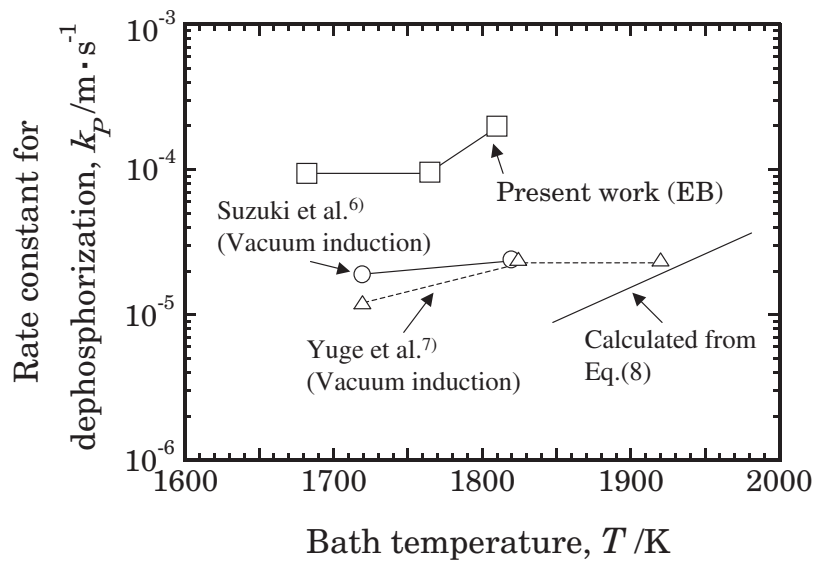

Fig. 9 Relation between rate constant for dephosphorization and bath temperature.

compares EB melting with the vacuum induction process investigated by Suzuki et al. ${ }^{6)}$ and Yuge et al., ${ }^{7)}$ and also includes the calculated results from eq. (6). The de-P rate is higher in EB melting than with the vacuum induction process at the same bath temperature because a locally higher temperature exists at the reaction interface (free surface of molten silicon) when an EB is applied to the melt. Thus, EB melting proved to be more effective for removing phosphorous from molten silicon.

\subsection{Continuous flow experiments}

\subsubsection{Flow pattern of continuous silicon feed}

Figure 10 shows the relationship between the phosphorous content at the exit of the hearth and the mean residence time, $\tau(\mathrm{s})$, in the hearth.

$$
\tau=V / F_{\mathrm{Si}}
$$

where $F_{\mathrm{Si}}$ is the molten silicon feed rate $(\mathrm{kg} / \mathrm{s})$ and the phosphorous content is that of MG-Si. From Fig. 10, the $P$ content increases when the silicon feed rate is raised because the mean hearth residence time of the silicon is proportionately shorter.

Dephosphorization behavior in the continuous flow experiment can be expressed as an n-stage mixed reactor system, as follows. ${ }^{16)}$

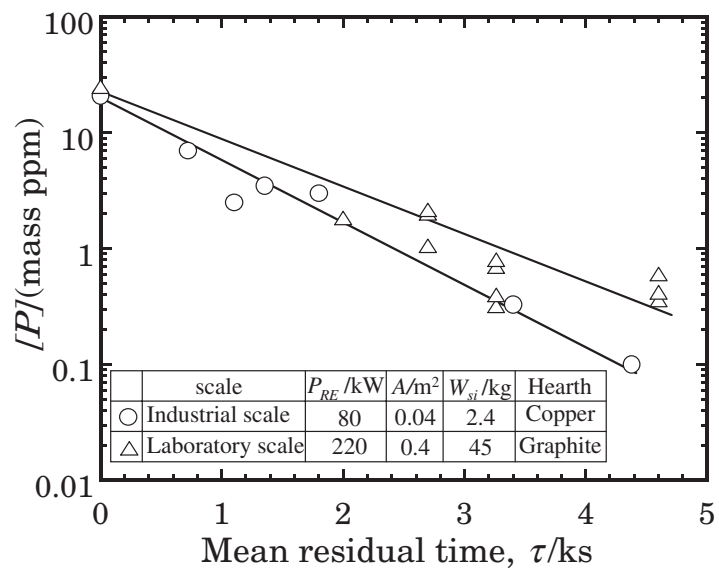

Fig. 10 Relation between phosphorus content and mean residual time.

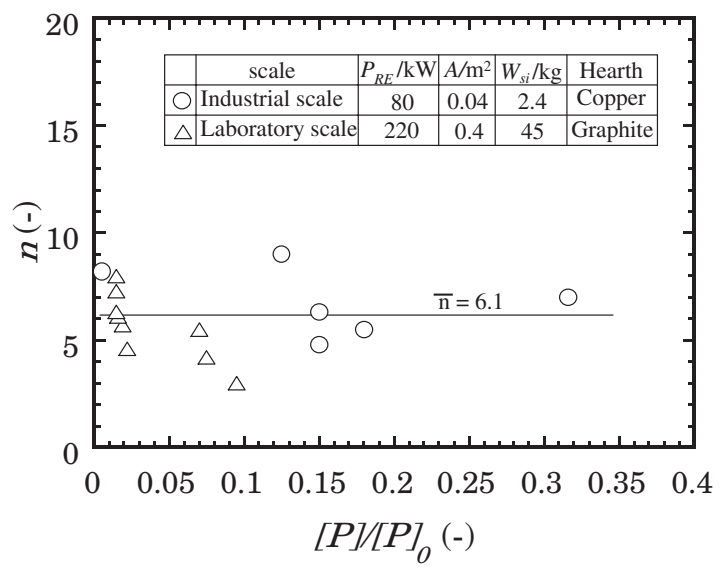

Fig. 11 Relation between $\mathrm{n}$ and phosphorus content at outlet.

$$
[P]_{0} /[P]=\left\{1+k_{\mathrm{P}}(A / V)(\tau / n)\right\}^{n}
$$

where $[P]_{0}$ is the initial $P$ content (mass ppm) and $n$ is the number of mixed reactors. Figure 11 shows the relationship between $n$ calculated from eq. (9) and $[P]_{0} /[P]$. The range and mean value of $\mathrm{n}$ are 3-9 and 6.1, respectively. According to eq. (9), the de-P rate is enhanced by larger values of $n$. Further, $n \rightarrow \infty$, that is, plug flow, is expected for a continuous silicon feed process.

\subsubsection{Continuous operation experiment with industrial scale equipment}

A continuous operation experiment was carried out with industrial scale equipment using an MG-Si feed rate of $45 \mathrm{~kg} / \mathrm{h}, \mathrm{EB}$ power at No. 2 graphite hearth of $250 \mathrm{~kW}$, and the other experimental conditions shown in Table 2. An EB power of $600 \mathrm{~kW}$ was irradiated on the molten silicon in the water-cooled copper mold for directional solidification. The sampling position in the silicon ingot obtained by directional solidification was the middle of the purified part. The change in $[P]$ in the silicon ingot is shown in Fig. 12. The mean value and standard deviation of $[P]$ in this campaign were 0.077 and 0.017 mass ppm, respectively, which achieved the target of below 0.1 mass ppm required for solar cells.

Figure 13 shows the silicon supply rate dependence of $[P]$ at the outlet of No. 2 hearth. Here, $[P]$ increases as the silicon supply rate increases. As shown in Fig. 13, to obtain the

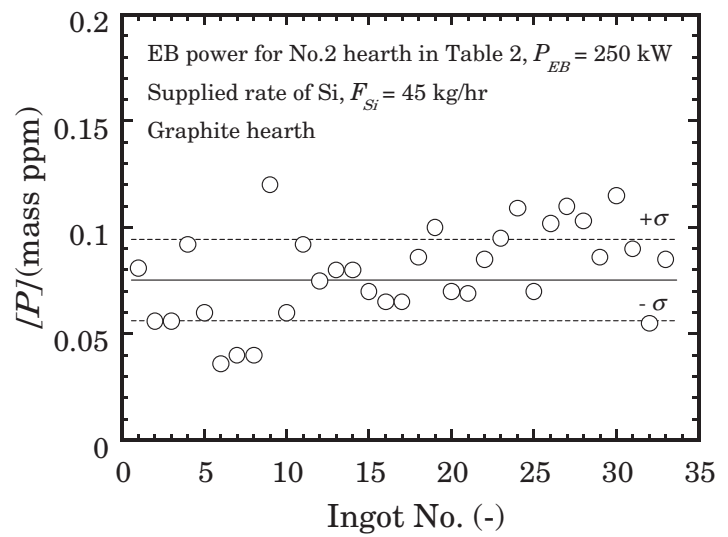

Fig. 12 Sequential phosphorus content in silicon ingots manufactured for trial. 


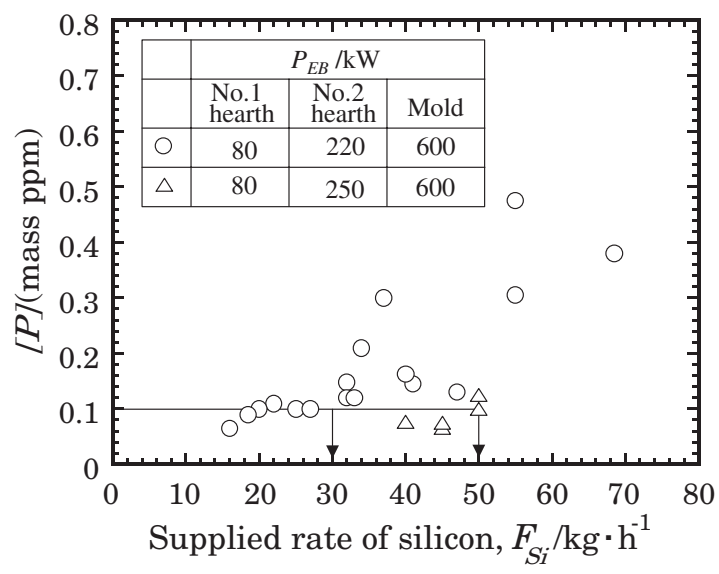

Fig. 13 Relation between phosphorus content and supplied rate of silicon.

required $[P]<0.1$ mass ppm with an EB power of $220 \mathrm{~kW}$, the silicon supply rate must be below $30 \mathrm{~kg} / \mathrm{h}$, whereas with $250 \mathrm{~kW}$, the supply rate must be below $50 \mathrm{~kg} / \mathrm{h}$.

\section{Conclusions}

The evaporation behavior of phosphorus in molten silicon during electron beam irradiation was investigated with the aim of producing SOG-Si from metallurgical MG-Si by a newly developed sequential metallurgical process, with the following conclusions.

(1) The dephosphorization reaction proceeds according to the first order rate law.

(2) The de- $P$ rate increases with increasing EB power density (power per surface area of molten silicon in the hearth).

(3) The surface temperature of the molten silicon is estimated to be $250-400 \mathrm{~K}$ higher than the molten silicon bath temperature.

(4) The de- $P$ rate is controlled by free evaporation through the surface of the molten silicon.

(5) The flow pattern of the molten silicon in the hearth did not behave as a complete mixed flow type reaction, but was close to a plug flow type reaction.

(6) With $150 \mathrm{~kg}$ scale equipment, MG-Si containing approximately 25 mass ppm of phosphorus was successfully purified to $\mathrm{P}<0.1$ mass ppm.

\section{Acknowledgements}

This work was supported by Japan's New Energy and Industrial Technology Development Organization (NEDO) and Agency of Natural Resources and Energy. The authors wish to thank Prof. Emeritus N. Sano of the University of Tokyo, Prof. T. Saitoh of Tokyo A\&T University, and Dr. F. Aratani of the former SOG-Si Technology Research Association for discussion of technical questions.

\section{REFERENCES}

1) Y. Kato, K. Hanazawa, H. Baba, N. Nakamura, N. Yuge, Y. Sakaguchi, S. Hiwasa and F. Aratani: Tetsu-to-Hagane 86 (2000) 717-724.

2) N. Nakamura, H. Baba, Y. Sakaguchi and Y. Kato: Mater. Trans. 45 (2004) 858-864.

3) Y. Sakaguchi, H. Terashima and F. Aratani: Shinsozai 5 (1994) 39-43.

4) J. Fally, E. Fabre and B. Chabot: Rev. Phys. Appl. 22 (1987) 529-534.

5) F. A. Trumbore: Bell Syst. Tech. J. 39 (1960) 205-233.

6) K. Suzuki, K. Sakaguchi, T. Nakagiri and N. Sano: J. Japan Inst. Metals 54 (1990) 161-167.

7) N. Yuge, K, Hanazawa, K. Nishikawa and H. Terashima: J. Japan Inst. Metals 61 (1997) 1086-1093.

8) T. Ikeda and M. Maeda: ISIJ Int. 32 (1992) 635-642.

9) N. Yuge, K. Hanazawa and Y. Kato: Mater. Trans. 45 (2004) 850-857.

10) O. Kubachewski and C. B. Alock: Metallurgical Thermochemistry, 5th Ed., (Pergamon Press Ltd., New York, 1979) p. 372.

11) K. Yanaba, M. Akasaka, M. Taguchi, M. Watanabe, T. Narushima and Y. Iguchi: Mater. Trans., JIM 38 (1997) 990-994.

12) R. Nakao, S. Fukumoto, M. Fuji and H. Takeuchi: ISIJ Int. 32 (1992) 685-692.

13) S. Watakabe, K. Suzuki and K. Nishikawa: ISIJ Int. 32 (1992) 625-629.

14) T. Isawa, H. Nakamura and K. Murakami: ISIJ Int. 32 (1992) 607-615.

15) T. Miki, K. Morita and N. Sano: Metall. Trans. B 27B (1996) 937-941.

16) O. Levenspiel: Chemical Reaction Engineering, 2nd Ed., (John Wiley \& Sons, New York, 1972) p. 136. 